\title{
AVALIAÇÃO TÁCTICA NO VOLEIBOL - O POSICIONAMENTO DEFENSIVO E ZONAS VULNERÁVEIS EM FUNÇÃO DA ZONA DO ATAQUE ADVERSÁRIO NO 5 JOGO DA FASE FINAL DO PLAY-OFF DIVISÃO A1
}

\begin{abstract}
AUTORES
Francisco Gonçalves ${ }^{1}$

Paulo Mourão ${ }^{2}$

${ }^{1}$ Licenciado e Doutorando em Educação Física e Desporto pela Universidade de Trás-os-Montes e Alto Douro

${ }^{2}$ Licenciado em Educação Física pelo ISMAI e Mestre em Ciências do Desporto pela Universidade de Trás-os-Montes e Alto Douro
\end{abstract}

AVALIAÇÃO TÁCTICA NO VOLEIBOL - O POSICIONAMENTO DEFENSIVO E ZONAS VULNERÁVEIS EM FUNCCÃO DA ZONA DO ATAQUE ADVERSÁRIO NO 5 JOGO DA FASE FINAL DO PLAY-OFF DIVISÃO A1 4(4): 51-58

PALAVRAS-CHAVE

voleibol; organização táctica defensiva; zonas vulneráveis.

KEYWORDS

volleyball; defensive tactic organization; vulnerable zones.
RESUMO

Para atingir o objectivo do jogo de Voleibol, os jogadores devem executar acções individuais, que numa estrutura específica, formam o pensamento táctico. Assim, é importante verificar as acções de jogo, neste caso o pensamento táctico defensivo para encontrar a melhor forma para o contrariar.

0 presente estudo, pretende analisar a organização táctica defensiva, assim como o local de embate da bola no solo, em função da zona de ataque, tentando encontrar um padrão de zonas vulneráveis.

Foram analisadas as acções ofensivas que originaram ponto directo, das equipas presentes no $5^{\circ}$ jogo da final do Play-Off (Sport Lisboa e Benfica e Sporting Clube de Espinho], do campeonato de sénior masculino de Voleibol. Foi analisado o posicionamento defensivo da equipa, assim como o local de embate da bola, dividindo-se o campo em 9 zonas defensivas.

Concluiu-se que as zonas defensivas do Benfica mais vulneráveis são as áreas mais próximas da linha dos 3 metros. Por sua vez, o Espinho apresenta vulnerabilidade no centro e na esquerda, atrás da linha dos 3 metros.

A pertinência desta análise táctica quantitativa, permite determinar como deverá ser planeada a estrutura táctica ofensiva das equipas adversárias, com o intuito de procurar explorar estas zonas vulneráveis.

\section{ABSTRACT}

To hit the Volleyball game's objective, the players must perform individual actions that in a specific structure form the tactic thought. Thus, it is important to verify the game's actions, in this case the defensive tactic thought to find the best form to oppose it.

The present study, intends to analyze the defensive tactic organization, as well as the place of touch of the ball in the ground, in function of the attack zone, trying to find a vulnerable zones standard.

The offensive actions that had originated direct point, of the teams presents in $5^{\circ}$ game of the end of the Play-Off, of the championship of masculine senior of Volleyball (Sport Lisboa e Benfica and Sporting Club de Espinho], had been analyzed. The defensive positioning of the team was analyzed, as well as the place of touch of the ball, dividing the field in 9 possible defensive zones.

We concluded that the Benfica's defensive zones most vulnerable are the areas next to the line of the 3 meters. In turn, the Espinho presents vulnerability in the centre and the left, behind the line of the 3 meters.

The relevancy of this quantitative tactic analysis, allows to determine as the offensive tactic structure will have to be plan by the adversaries teams, with intention to explore these vulnerable zones. 


\section{INTRODUC̣ÃO}

Para atingir o objectivo do jogo de Voleibol, os jogadores executam acções individuais, que numa estrutura específica formam o pensamento táctico. Este pensamento táctico deve estar sempre presente ao longo do jogo e caracteriza-se pela comunicação e cooperação' No nosso estudo, como mais à frente veremos, o objectivo é o de verificar a relação com o adversário, sendo então importante a contra-comunicação e a oposição. Assim, é importante verificar as accõoes de jogo que a equipa que se encontra no processo defensivo leva a cabo, para contrariar o ataque adversário, através de acções de jogo individuais e colectivas.

Estas acções encontram-se determinadas por modelos e princípios específicos, que poderão variar consoante os elementos da equipa, adversário e características de jogo'.

0 ataque é definido como a tentativa de ultrapassar a defesa, colocando a bola do lado contrário, dentro do terreno de jogo e fora do alcance da equipa adversária, cumprindo todas as regras do jogo ${ }^{3}$.

Por sua vez, a defesa é definida como a tentativa de evitar a concretização de ponto por parte da equipa adversária, tentando recuperar a bola, para concretizar. Em suma, a defesa é a reacção ao ataque ${ }^{3}$.

Desta forma, cada equipa deve organizar-se ofensiva e defensivamente. A esta organização está designado o conceito de táctica.

A situação táctica ofensiva deve procurar encontrar zonas vulneráveis na organização defensiva adversária, que lhes permita colocar a bola fora do alcance do adversário. Na situação táctica defensiva, a equipa luta para não permitir ao adversário a conquista do ponto, e consequente recuperação da posse de bola para o ataque ${ }^{2}$.
0 estudo efectuado pretende analisar a organização táctica defensiva, em função da zona de ataque, tentando encontrar um padrão de zonas vulneráveis. Assim, contabilizaremos em termos esquemáticos somente o momento em que o ponto for obtido, através do contacto da bola no solo, directamente proveniente do ataque, não havendo possibilidade de defesa.

Existem condicionantes regulamentares inerentes a todo este processo, tais como a marcação de pontos, a obrigatoriedade de rotação de jogadores e as zonas de jogo. Assim sendo, cada técnico terá de estruturar a sua equipa com base nestas limitações, de forma a obter sucesso.

Com base na bibliografia analisada e nas aparentes necessidades de estudos baseados na análise táctica defensiva no Voleibol, decidimos analisar os sistemas tácticos defensivos das duas equipas finalistas do campeonato de Voleibol da época 2004/2005, no momento da concretização de pontos do respectivo adversário.

As equipas analisadas correspondiam ao escalão sénior masculino, a disputar o $5^{\circ}$ jogo da final do Play-Off, do Campeonato Sénior Masculino em Voleibol A1; Sporting Club de Espinho Vs. Sport Lisboa e Benfica, na época 2004/2005.

\section{METODOLOGIA}

\subsection{Amostra}

A amostra é constituída por 2 equipas do escalão sénior masculino, a disputar a final do Play-Off do Campeonato Sénior Masculino em Voleibol na época 2004/2005, entre o Sporting Club de Espinho e o Sport Lisboa e Benfica.

\subsection{Equipamento}

Para a realização deste trabalho foi utilizada um televisor SONY BlackTriniton, um Vídeo Gravador SONY BlackTriniton de 4 cabeças e uma cassete de vídeo JVC de 240 minutos.

\subsection{Procedimentos experimentais}

Foram definidas 6 zonas de ataque (figura 1), para análise do local de ataque, e 9 zonas de defesa, para a análise do local de queda da bola e da colocação dos jogadores defensores (figura 2).

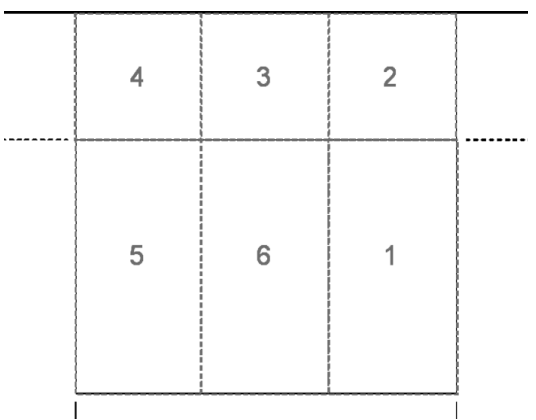

FIGURA1 Divisão do campo em 6 zonas possíveis de ataque.

Optou-se por dividir o campo defensivo, em 9 zonas, pelo simples facto de ser aparentemente mais válido.

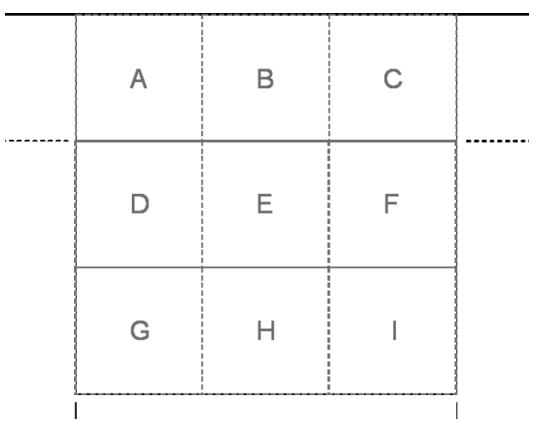

FIGURA2 Divisão do campo em 9 zonas possiveis de queda da bola e de colocação dos jogadores defensores. 
Só foram contabilizadas as acções ofensivas que tiveram como consequência o ponto directo (bola directamente para o solo], sem possibilidade de defesa.

No momento de finalização, foi analisado o posicionamento de cada um dos 6 jogadores da equipa defensiva, nas 9 possíveis zonas de defesa, com o intuito de analisar a sua organização táctica defensiva e detectar zonas vulneráveis. Para a análise quantitativa das acções previamente definidas, procedemos à análise do produto (posicionamento defensivo da equipa, aquando do remate adversário]. Consequentemente, houve ainda a análise do local de embate da bola no solo, igualmente uma análise quantitativa.

Em termos de definição do contexto de recolha de dados, tentámos seleccionar os indicadores mais adequados às nossas necessidades. Assim, não nos preocupámos em analisar muitos aspectos do jogo, mas sim uma variável objectiva (como já foi referenciado, local de embate da bola no solo].

Em termos de validade aparente, a forma utilizada, permitiu medir aquilo a que se propôs, além do mais, em termos de fiabilidade, a utilização do vídeo permite reduzir ao máximo a fonte de erro, havendo consistência na análise. Sendo o grupo constituído por dois elementos, cada um analisou, independentemente as acções de jogo e só posteriormente se compararam os resultados. No caso das observações serem díspares, houve uma terceira análise conjunta para dissipação completa de dúvidas e haver um aumento da objectividade.
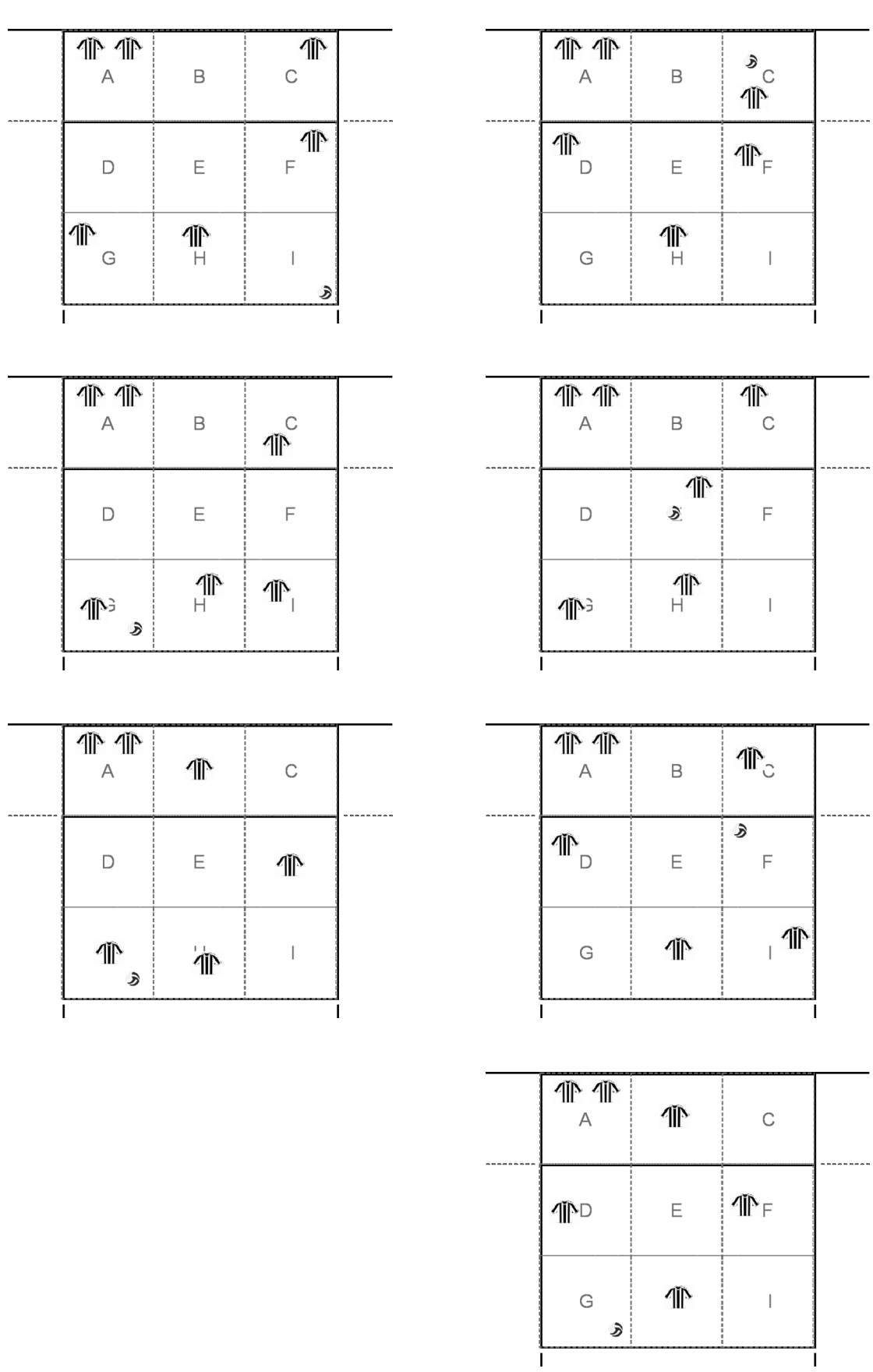

FIGURA3

Posicionamento Defensivo do Espinho nos remates de zona 2 do Benfica. 

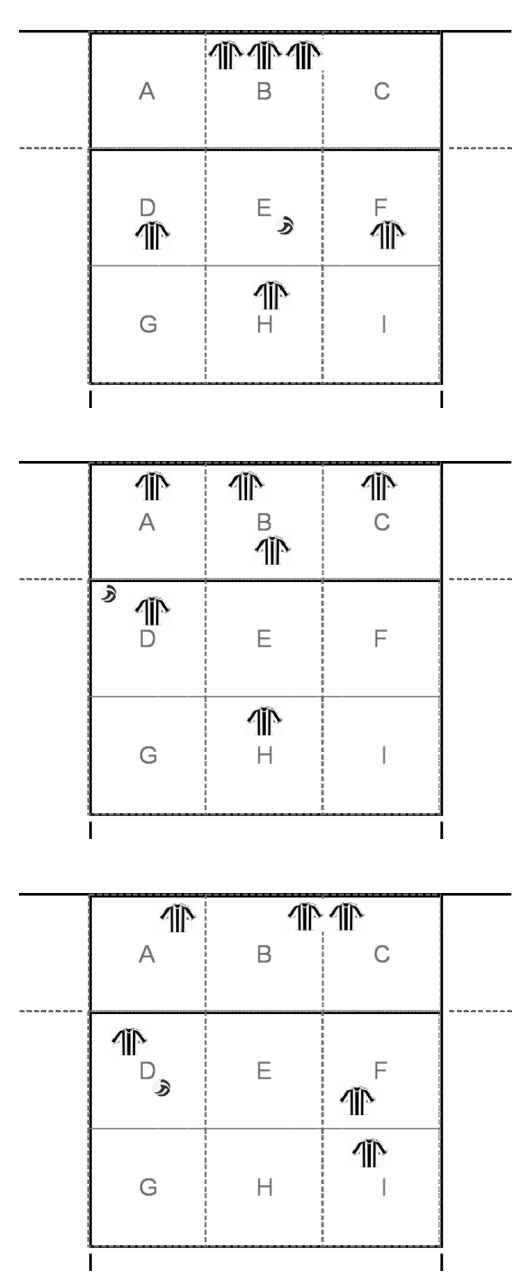
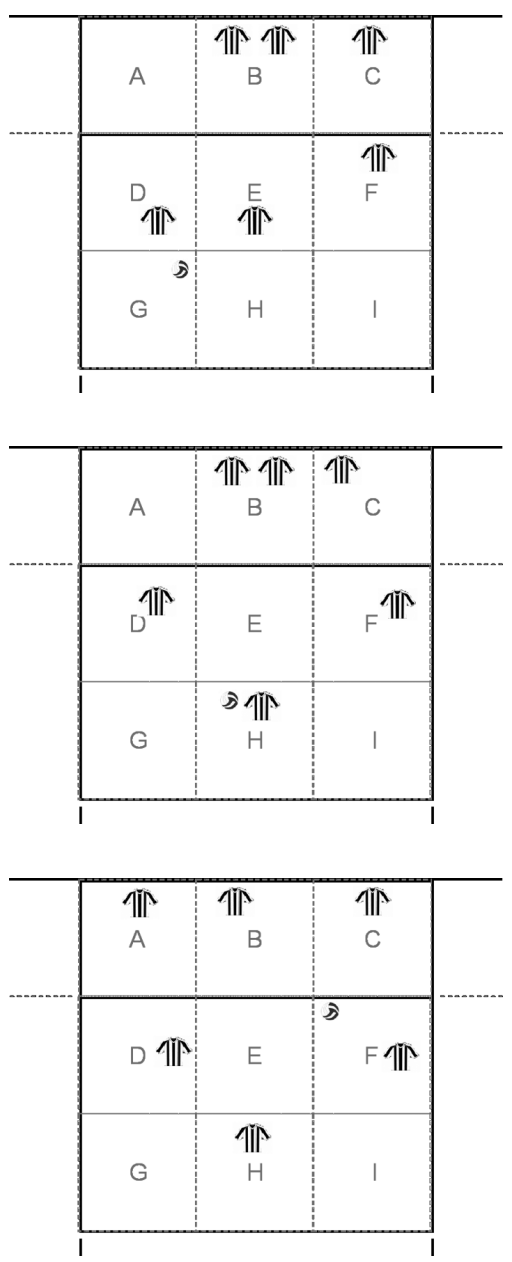

FIGURA4

Posicionamento Defensivo do Espinho nos remates de zona 3 do Benfica.

\section{RESULTADOS}

Os resultados serão divididos em duas partes e dizem respeito a todo o jogo (4 sets). Na primeira, apresentar-se-ão os resultados referentes à avaliação táctica da equipa do Espinho. Naturalmente que neste momento a equipa adversária detém a posse de bola e prepara o ataque. Das 6 zonas previamente estabelecidas como possíveis zonas de remate, o Benfica utilizou somente 3 , a zona 2 , zona 3 e zona 4 . Nos 7 momentos do remate concretizados pelo Benfica da zona 2, a disposição táctica do Espinho foi a seguinte (ver figura 3).
Da zona 3, o Benfica realizou 6 remates, concretizando-os em ponto. Nesses momentos a disposição táctica do Espinho foi a seguinte (ver figura 4).

Da zona 4, o Benfica realizou 7 remates, todos eles concretizados com a bola a embater no solo. Nesses momentos a disposição táctica do Espinho foi a seguinte (ver figura 5).

Como foi referenciado anteriormente, nesta segunda parte da apresentação esquemática dos resultados, ir-se-ão analisar os resultados referentes à avaliação táctica da equipa do Benfica. Das 6 zonas previamente estabelecidas como possíveis zonas de remate, o Benfica, à imagem do Espinho, utilizou somente 3 , a zona 2 , zona 3 e zona 4 . Nos 7 momentos do remate concretizados pelo Espinho da zona 2, a disposição táctica do Benfica foi a seguinte (ver figura 6). Da zona 3, o Espinho realizou 9 remates, concretizando-os em ponto. Nesses momentos a disposição táctica do Benfica foi a seguinte (ver figura 7).

Da zona 4, o Espinho realizou 5 remates, todos eles concretizados com a bola a embater no solo. Nesses momentos a disposição táctica do Benfica foi a seguinte [ver figura 8). 


\section{DISCUSSÃO}

Através da análise dos remates do Benfica da zona 2, podemos verificar algumas lacunas em alguns locais da defesa do Espinho. Assim, podemos verificar as zonas onde 0 ponto foi marcado, logo zonas onde a defesa não foi eficaz. A zona defensiva mais permeável ao ataque adversário foi a zona $G$, havendo três bolas a concretizar ponto nesta zona. Podemos ainda verificar que 0 ataque para a diagonal curta também surtiu efeito (zonas C, $\mathrm{F}$ e E].

No que à zona 3 diz respeito, a permeabilidade defensiva do Espinho fez-se notar mais no quadrante defensivo esquerdo, contemplado pelas zonas $\mathrm{D}, \mathrm{E}, \mathrm{G}$ e $\mathrm{H}$.

Os remates da equipa do Benfica provenientes da zona 4, resultaram numa vulnerabilidade defensiva por parte da equipa do Espinho, maioritariamente na zona $\mathrm{H}$, com três bolas; e na zona $\mathbf{D}$ com duas bolas. (ver figura 9).

Em suma, e indo ao encontro do objectivo do presente trabalho, podemos constatar que as zonas defensivas do Espinho mais vulneráveis são as zonas $\mathrm{D}, \mathrm{E}, \mathrm{G}$ e $\mathrm{H}$.

Através da análise dos remates do Espinho da zona 2, podemos verificar também algumas lacunas
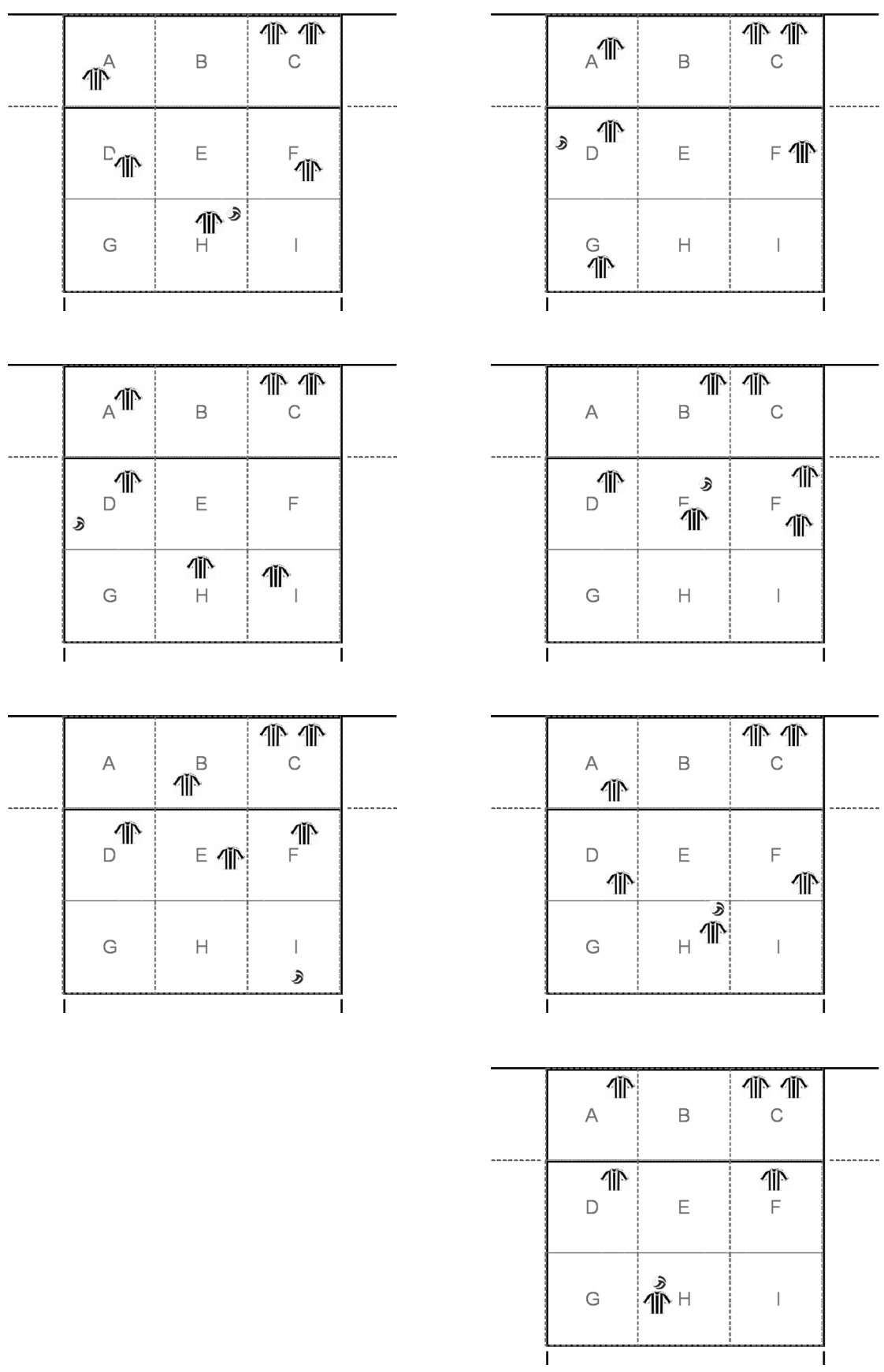

FIGURA5

Posicionamento Defensivo do Espinho nos remates de zona 4 do Benfica. 

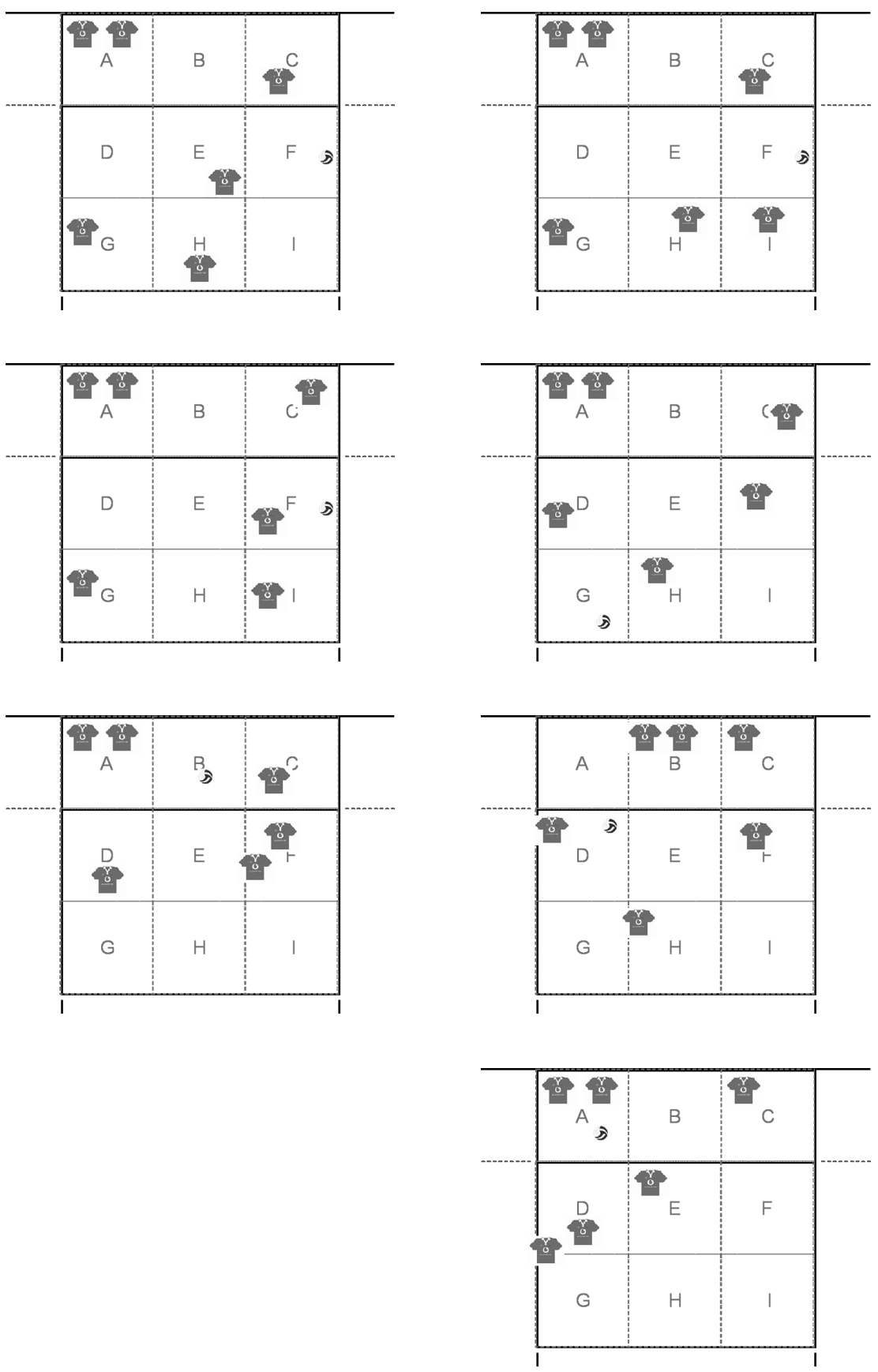

FIGURA6

Posicionamento Defensivo do Benfica nos remates de zona 2 do Espinho. defensivas do Benfica. A zona defensiva mais permeável ao ataque adversário foi a zona $F$, havendo três bolas a concretizar ponto nesta zona. Podemos ainda verificar que $o$ ataque para a zona $A, B$ e $D$ também surtiu efeito, com uma bola em cada zona.

No que diz respeito à zona 3 , a permeabilidade defensiva do Benfica fez-se notar mais na área composta pelas zonas D, E e F. Para além deste facto, existe maior permeabilidade no lado direito. De salientar ainda, que este foi o parâmetro analisado em que houve mais ocorrências (9 remates). Assim, podemos supor que o ataque do Espinho da zona 3 é bastante eficaz, ou eventualmente a defesa do Benfica apresenta lacunas perante uma ataque deste tipo.

Os remates da equipa do Espinho provenientes da zona 4, resultaram numa vulnerabilidade defensiva por parte da equipa do Benfica, tendencialmente, no lado esquerdo, ou seja perante remates cruzados. (ver figura 10).

Em suma, e indo ao encontro do objectivo do presente trabalho, podemos constatar que as zonas defensivas do Benfica mais vulneráveis são as zonas $\mathrm{D}$ e $\mathrm{F}$. De salientar ainda que os ataques para a proximidade da linha dos 3 metros foram bastante eficazes, ou seja, existe vulnerabilidade nesta zona. A pertinência desta análise táctica quantitativa, permite determinar como deverá ser planeada a estrutura táctica ofensiva das equipas adversárias, com o intuito de procurar explorar estas zonas vulneráveis. 
Revista de Desporto e Saúde
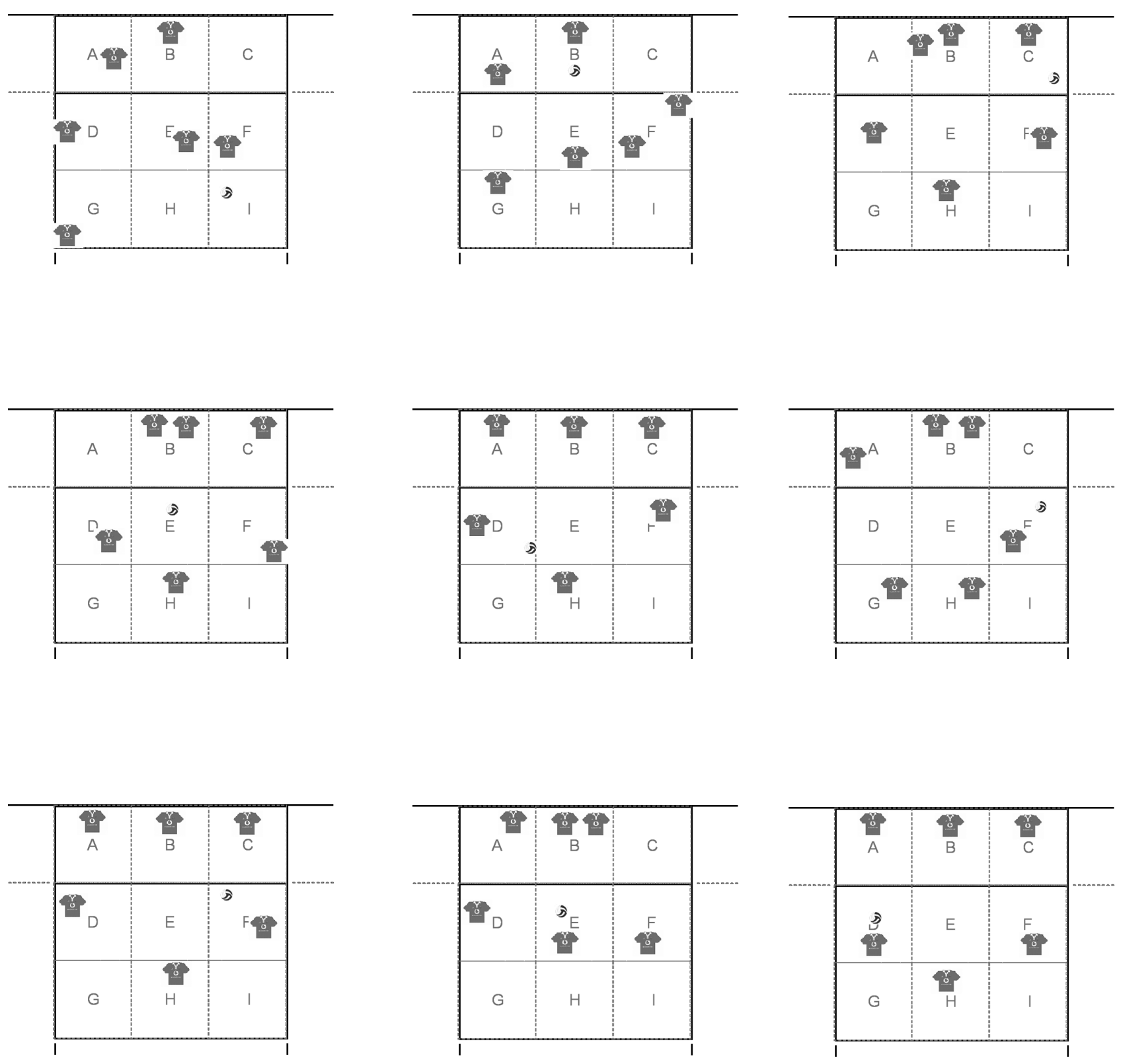

FIGURA7 

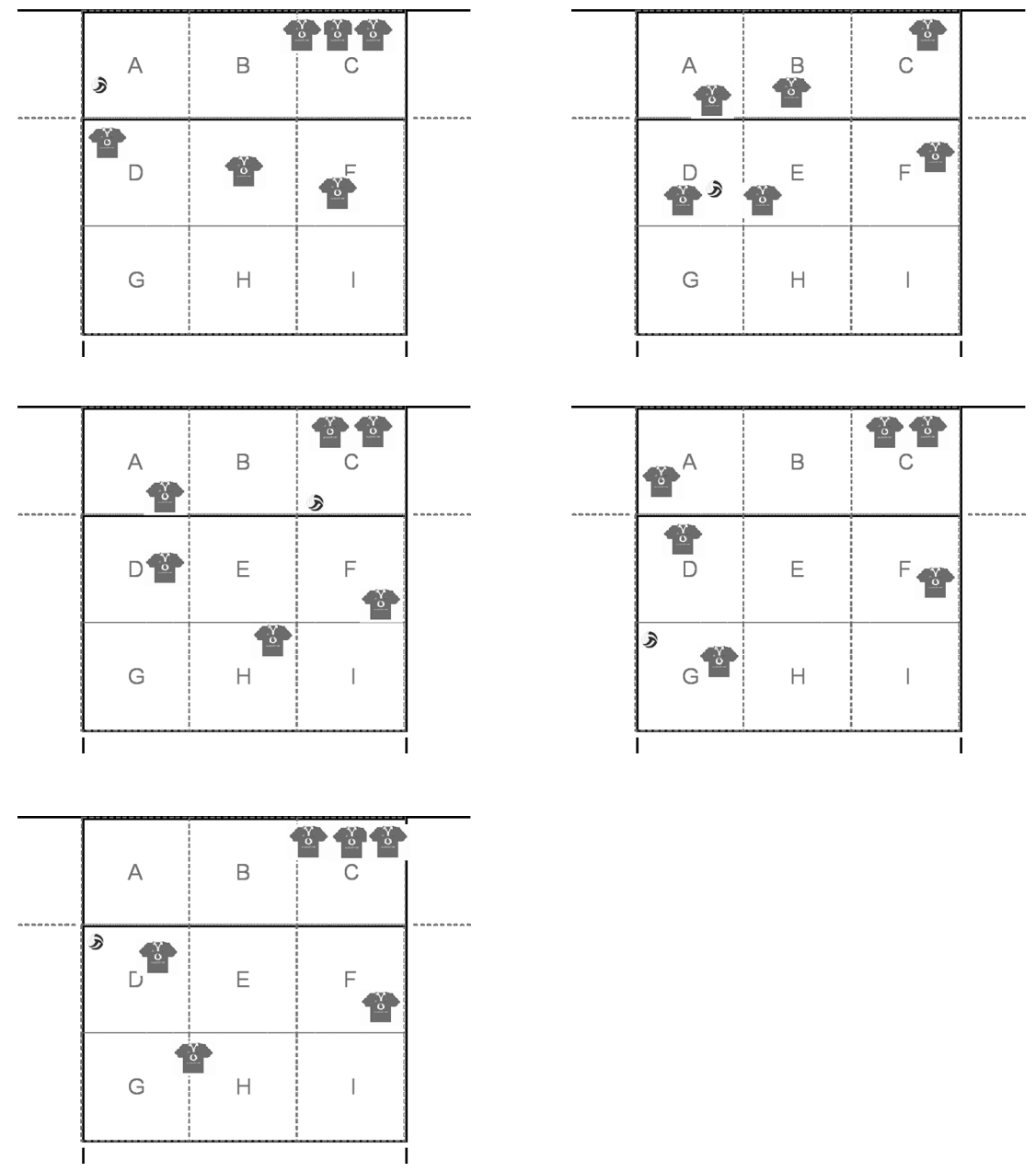

\section{CORRESPONDÊNCIA}

Francisco Gonçalves

Travessa Comendador Seabra da Silva, n. ${ }^{\circ} 226$

3720-297 Oliveira de Azeméis

E-mail: franciscojmg@gmail.com xicoze7@hotmail.com

TIms: 917668858 966833562

TIf.: 256285335

\section{REFERÊNCIAS}

1. Moutinho CA (1998). 0 ensino do Voleibol. A estrutura funcional do Voleibol. In Graça A., Oliveira. J. O Ensino dos Jogos Desportivos.

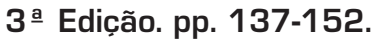

2. Mesquita I (1998). O ensino do Voleibol. Proposta Metodológica. In Graça A., Oliveira. J. O Ensino dos Jogos Desportivos. $3{ }^{a}$ Edic̣ão. Pp. 153-199.

3. Shondell, D., Reinaud, C. (2002) The Volleyball Coaching Bible. Human Kinetics Publishers Inc.: Champaign, IL, USA.

FIGURA8 Posicionamento Defensivo do Benfica nos remates de zona 4 do Espinho.

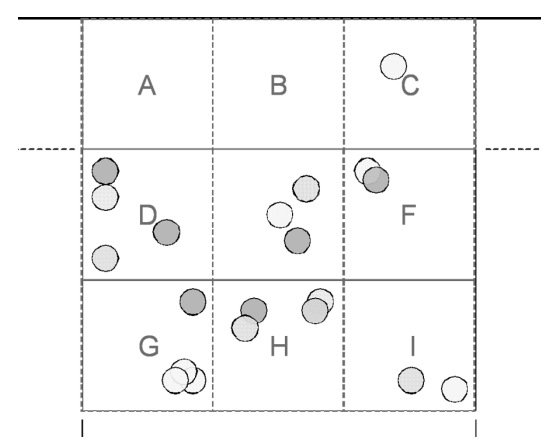

Ataque de $Z 2$

Ataque de $Z 3$

Ataque de $Z 4$

FIGURA9 Vulnerabilidade defensiva do Espinho em função da zona de ataque.

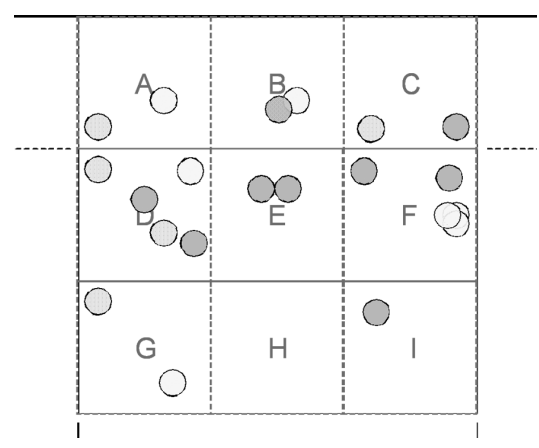

Ataque de $Z 2$

Ataque de $Z 3$

Ataque de $Z 4$

FIGURA10 Vulnerabilidade defensiva do Benfica em função da zona de ataque. 